\title{
Assembling Nanoparticle Clusters by Kinetic Control Using Weakly Interacting DNA Linkages
}

\author{
Alisha J. Lewis and Mathew M. Maye* \\ Department of Chemistry, Syracuse University, Syracuse New York 13244 U.S.A. \\ *mmmaye@syr.edu
}

\begin{abstract}
In this paper, we describe the use of weakly interacting DNA linkages to assemble nanoparticles into defined clusters. Gold nanoparticles (AuNPs) were synthesized and functionalized with thiol modified single-stranded DNA (ssDNA) and hybridized with ssDNA linkers of a defined length (L). The self-assembly kinetics were altered by manipulating interparticle energetics through changes to linker length, rigidity, and sequence. The linker length regulated the hybridization energy between complementary AuNPs, were longer L increased adhesion, resulting in classical uncontrollable aggregation. In contrast, L of six complementary bases decreased adhesion and resulting in slower nucleation that promoted small cluster formation, the growth of which was studied at two assembly temperatures. Results indicated that a decrease in temperature to $15^{\circ} \mathrm{C}$ increased cluster yield with $\mathrm{L}_{6}$ as compared to $25^{\circ} \mathrm{C}$. Finally, the clusters were separated from unassembled AuNPs by sucrose gradient ultracentrifugation (UC) and studied via UV-visible spectrophotometry (UV-vis), dynamic light scattering (DLS) and transmission electron microscopy (TEM).
\end{abstract}

Keywords: Self-Assembly, DNA, Kinetic Control, Linker, Ultracentrifugation, Nanomaterials, Nanoparticles 


\section{Introduction}

The fabrication of nanoscale structures has been widely explored across many disciplines including chemistry, physics, and materials science. Nanomaterials self-assembled from the bottom-up ${ }^{1-3}$ have utilized intrinsic assembly properties of proteins, ${ }^{4}$ polymers ${ }^{5-7}$ and DNA. ${ }^{8-10}$ DNA has been shown to be a particularly interesting nanofabrication tool due to its inherent programmability and sequence specificity, and used to facilitate assembly in both a direct ${ }^{11-14}$ and templated manners. ${ }^{15-17}$ Assembly properties of DNA have been harnessed to readily and reversibly self-assemble nanoparticles (NPs) including, metal NPs, ${ }^{18-21}$ magnetic NPs ${ }^{22}$ and semiconductive quantum materials like quantum dots $(\mathrm{QD})^{23}$ and quantum rods $(\mathrm{QR})^{24}$ with unique tailorability. For example, it was shown that interactions between these NPs can be tuned by manipulating assembly parameters such as DNA length, ${ }^{25} \mathrm{NP}$ concentration and ionic strength $^{26}$ to alter interparticle distances, ${ }^{27}$ thermal denaturation temperatures ${ }^{28}$ and hybridization kinetics. ${ }^{29-31}$

Such assembly considerations open new avenues of research leading to the development of unique approaches, which strategically design these nanomaterials into specified conformations or morphologies. Recently, researchers have shown that finite NP assembly can be manipulated with special consideration to NP size, ${ }^{32}$ assembly molar ratio ${ }^{33}$ and interacting surface ligands. ${ }^{34}$ For instance, packing parameters associated with spherical NPs can limit growth of an assembly solely through manipulations to the particles diameter. Alternatively, application of limited number of DNA on the NP surface can also induce controlled morphologies due to the limited strands available for assembly. ${ }^{35,36}$ These approaches however often involve multiple DNA sequences, step-wise assembly schemes and laborious purification procedures. 
One potentially advantageous hybridization scheme is to assemble uniform, DNA-capped NPs with maximum functionalization, into discrete clusters, in a simple, straightforward manner, where cluster morphology can be controlled and isolated. Manipulations to interparticle energies, achieved through changes in the DNA sequence and length, can set the scale of adhesion between the NPs and control both the hybridization kinetics and subsequent stability of the NP clusters. $^{37-40}$ Previous reports have shown that purification of discrete gold NP (AuNP) assemblies is achievable via agarose gel electrophoresis, ${ }^{41}$ anion-exchange high-performance liquid chromatography (HPLC) $)^{42}$ and chemical gradient centrifugation. ${ }^{43}$

In this work, we focus on the assembly properties of AuNPs with scalable DNA linkages. Two AuNP batches capped with non-complementary DNA strands are assembled solely with the addition of a DNA linker (L) with recognition sequences ranging from 6-15 bases. We show that kinetics of assembly can be controlled as a function of this L length. Further, implementation of scalable L, resulting in tailorable interparticle energies, also promotes changes to AuNP assembly size. We further show that a decrease in assembly temperature, influences the morphology and stability of the assembly, which in turn, results in an increase in population (\%) of discrete AuNP clusters. 


\section{Experimental Details}

Chemicals: Single stranded oligonucleotides (ssDNA) were purchased from Integrated DNA Technologies. Hydrogen tetracholoraurate hydrate (99.99\%), Sodium phosphate dibasic heptahydrate (98.0-102.0\%), Sodium phosphate monobasic monohydrate (98.0-102.0\%), Sodium citrate tribasic dihydrate (cit, 99\%), 10x TAE buffer and D-L-Dithiothreitol (DTT, 98\%) were purchased from Sigma Aldrich. Sodium chloride (NaCl, 99\%) was purchased from Fischer. Sucrose (Lab Grade, 98\%) was purchased from Ward Scientific and used without further purification. Ultrapure water (18.2 M $\Omega$ ) was prepared by a Sartorius Stedim Arium 61316 reverse osmosis unit combined with an Arium 611DI polishing unit.

DNA Purification: Thiol single stranded DNA, ssDNA, (IDT) was reduced with $200 \mu \mathrm{L}$ of 100mM DTT for 30 minutes. The DNA strands were subsequently run through a G-25 Sephadex column and eluted with $10 \mathrm{mM}$ phosphate buffer $(\mathrm{pH}=7.4)$. The eluted DNA fractions were analyzed utilizing both UV-Vis and specified DNA extinction coefficient, to determine concentration.

Gold Nanoparticle Synthesis (12nm): Gold nanoparticles (Au, $12 \pm 2 \mathrm{~nm}$ ) were synthesized via a modified citrate reduction procedure. ${ }^{29}$ Briefly, $50 \mathrm{~mL}$ of gold (III) chloride $\left(\mathrm{HAuCl}_{4}, 1 \mathrm{mM}\right)$ was heated to $100^{\circ} \mathrm{C}$ and allowed to boil for $30 \mathrm{~min}$. A separate solution of trisodium citrate (cit, $38 \mathrm{mM}$ ) was warmed and added to the reaction vessel in one aliquot with stirring. Upon color change to red the vessel was removed from heat and left to cool, stir and anneal overnight. Gold 
nanoparticle concentrations were measured using UV-Vis spectroscopy with an extinction coefficient of $1.0 \times 10^{8} \mathrm{M}^{-1} \mathrm{~cm}^{-1}$ through the Beer-Lambert correlation.

DNA-Nanoparticle Functionalization: Separate batches of citrate-capped AuNPs (cit-AuNPs) were functionalized with complementary ssDNA sequences. ${ }^{34}$ Briefly, a $1 \mathrm{~mL}$ aliquot cit-AuNPs was functionalized with the $\mathrm{A}\left(5^{\prime}-\mathrm{S}-\mathrm{CH}_{3}-\mathrm{TTT}\right.$ TTT TTT TTT TTT TAA CCT AAC CTT CAT3') DNA strand, containing a $15 \mathrm{~b}$ spacer region and a $15 \mathrm{~b}$ binding sequence. A second $1 \mathrm{~mL}$ AuNP aliquot was functionalized with the $\mathrm{B}\left(5^{\prime}-\mathrm{S}-\mathrm{CH}_{3}-\mathrm{TTT}\right.$ TTT TTT TTT TTT ATG AAG GTT AGG TTA- 3') DNA strand, containing the same number of spacer and binding bases. AuNPs were functionalized with excess DNA (200-500x) to ensure maximum coating. To maximize DNA surface coverage AuNPs were subject to a slow salt $(\mathrm{NaCl})$ aging process to 200mM. The salt aging process was necessary for effective screening of DNA charge repulsions of phosphate backbones between neighboring DNA strands, further ensuring maximum coverage. DNA-coated nanoparticles were cleaned respective speed and time (9000 RPM, 1hr) three times to rid the solution of excess DNA.

DNA Linker Functionalization: Previously functionalized A-AuNPs (1mL) were incubated with one of four complementary linker strands overnight. Each linker contained the same 15 base binding sequence complementary to A-AuNPs however each differed in the toehold region available for $\mathrm{B}-\mathrm{AuNP}$ binding. The $\mathrm{L}_{15}, \mathrm{~L}_{12}, \mathrm{~L}_{9}$, and $\mathrm{L}_{6}$ linkers have toehold regions of 15, 12, 9 and 6 bases, respectively. Table 1 summarizes each specified DNA sequence. To ensure maximum hybridization of linker on A-AuNP DNA strands, linkers were added in excess 
$([\mathrm{L}]:[\mathrm{A}-\mathrm{AuNP}]=80) . \mathrm{L}-\mathrm{A}-\mathrm{AuNPs}$ were cleaned at respective speeds $(9000 \mathrm{RPM}, 1 \mathrm{~h}$.$) three$ times to rid the solution of excess linker.

Table 1. Summary of both particle-bound thiol single-stranded DNA (ssDNA) and DNA-bound linker sequences used for discrete nanoparticle self-assembly strategy.

\begin{tabular}{ccc}
\hline Sequence Name & Sequence & \# of Bases \\
\hline A & 5'-S-CH -TTT TTT TTT TTT TTT TAA CCT AAC CTT CAT-3' $^{\prime}$ & 30 \\
B & 5'- ATT GGA TTG GAA GTA TTT TTT TTT TTT TTT-CH 3 -S-3' & 30 \\
$\mathrm{~L}_{15}$ & 5'-TAC TTC CAA TCC AAT ATG AAG GTT AGG TTA-3' & 30 \\
$\mathrm{~L}_{12}$ & 5'-TTC CAA TCC AAT ATG AAG GTT AGG TTA-3' & 27 \\
$\mathrm{~L}_{9}$ & 5'-CAA TCC AAT ATG AAG GTT AGG TTA-3' & 24 \\
$\mathrm{~L}_{6}$ & 5'-TCC AAT ATG AAG GTT AGG TTA-3' & 21
\end{tabular}

DNA Quantification: Previously functionalized A-AuNPs were quantified to determine the number of DNA strands present on an individual AuNP, using a Cy3 fluorescence procedure. Briefly, a sample of A-AuNPs was allowed to incubate with a complementary oligonucleotide strand containing a Cy3 fluorophore overnight $([\mathrm{Cy} 3]:[\mathrm{A}-\mathrm{AuNP}]=100)$. The $\mathrm{Cy} 3-\mathrm{A}-\mathrm{AuNPs}$ were centrifuged and the supernatant containing the excess unbound $\mathrm{Cy} 3$ fluorophore was collected and studied using fluorescence spectroscopy. Fluorescence was recorded and compared to Cy3 standardization curve to determine the number of DNA strands on the AuNP surface.

Sucrose Gradient: Sucrose concentrations (15-75\% w/v) were prepared separately. Each sucrose solution also contained $200 \mathrm{mM} \mathrm{NaCl}$ consistent with DNA salt aging. Roughly $700 \mu \mathrm{L}$ of each sucrose concentration was placed sequentially in a $5 \mathrm{~mL}$ ultracentrifugation tube and allowed to chill in the refrigerator overnight to create a sucrose gradient. Overnight chilling ensures proper gradient formation and gradient stability. AuNP samples were loaded atop the chilled gradient and allowed to spin at 10,000RPM for $10 \mathrm{~min}$. as to not pellet the system. Subsequent 
centrifugation spins were run at the same speed and time until optimum separation was achieved. AuNP bands were extracted and purified via dialysis overnight with buffer exchange.

\section{Instrumentation}

UV-Visible Spectrophotometry (UV-vis): UV-vis spectra were collected on Varian Cary50 Bio UV-Vis spectrophotometer between 200 and 800nm. Melting analysis was performed with a Varian Cary Temperature Controller and was preformed between $25-75^{\circ} \mathrm{C}$ with a temperature ramp of $1^{\circ} \mathrm{C} / \mathrm{min}$ while stirring.

Dynamic Light Scattering (DLS): The DLS results were measured using a Malvern Zetasizer ZS instrument. The instrument is equipped with a $522 \mathrm{~nm}$ laser source, and a backscattering detector at $173^{\circ}$. Data was analyzed using the CONTIN method.

Fluorescence: Fluorescence spectra were collected on a Horiba Jobin Yvon FluoroMax-4 SpectroFluorometer between 515 and $700 \mathrm{~nm}$. Experiments were performed with a 563nm light source, $3 \mathrm{~nm}$ slit width, and excitation at 500nm.

Agarose Gel Electrophoresis: Gel electrophoresis experiments were preformed using a conventional gel electrophoresis box with a VWR regulator. Gold nanoparticle samples were loaded to a $1 \%$ agarose gel in $1 \mathrm{x}$ TAE buffer, with applied voltage of $70 \mathrm{eV}$ for 45 minutes.

Transmission Electron Microscopy (TEM): TEM measurements preformed on a JOEL JSM2000EX electron microscope with an accelerating voltage between $80-120 \mathrm{~K}$ and a tungsten 
filament at the SUNY-ESF, N.C. Brown Center for Ultrastructure Studies. Particle analysis size analysis was completed with ImageJ on statistically relevant populations ( $\mathrm{n}>150)$. To analyze cluster morphology, a specialized image-processing package, FIJI was employed. The use of the BioVoxxel Toolbox ${ }^{44}$ allows for extended particle analysis and cluster indication software to help label and quantify the number of discrete clusters present in the selected TEM micrograph. The software analyzes particle clusters by detecting individual nanoparticle locations, distances between nearest neighbors, and particle densities to find, accept and map clusters in each image. Specifically, Gaussian Blur $=2.0$, cluster diameter $=12-50 \mathrm{~nm}$, cluster density $=6.0$, and iterations $=25$ were used for analyses.

Ultracentrifugation $(U C)$ : Sucrose separations were completed with use of a Beckman Coulter Optima Max-UP Ultracentrifuge at speeds of 10,000 RPM for $10 \mathrm{~min}$, using gradual $2.5 \mathrm{~min}$ acceleration and deceleration intervals. 


\section{Results and Discussion}

Scheme 1 illustrates the general self-assembly strategy employed in this study. Briefly, citrate-capped gold nanoparticles (AuNPs) were functionalized with two types of ssDNA, type -A and -B following standard methods. ${ }^{34,45,46,37,47,48} \mathrm{~A}-$ AuNPs were then further hybridized with a ssDNA linker (L) with 15 bp complementarity to -A, but varying in complementarity from 615 bp $\left(\mathrm{L}_{6}-\mathrm{L}_{15}\right)$ to $\mathrm{B}-\mathrm{AuNPs}$. By varying L, effective attraction (hybridization energy, E) between A- and B- AuNP was attenuated, from $-25.88 \mathrm{kCal}$ for $\mathrm{L}_{15}$, to $-10.02 \mathrm{kCal}$ at $\mathrm{L}_{6}$. In this embodiment, the $\mathrm{E}$ decrease can be manifested in lower thermal denaturation temperatures $\left(\mathrm{T}_{\mathrm{m}}\right)$, but also in decreased self-assembly kinetics, which, which may in turn may lead to different assembly sizes (i.e., cluster growth).

\section{Scheme 1. Idealized Assembly Schematic for Discrete Nanoparticle Clustering}

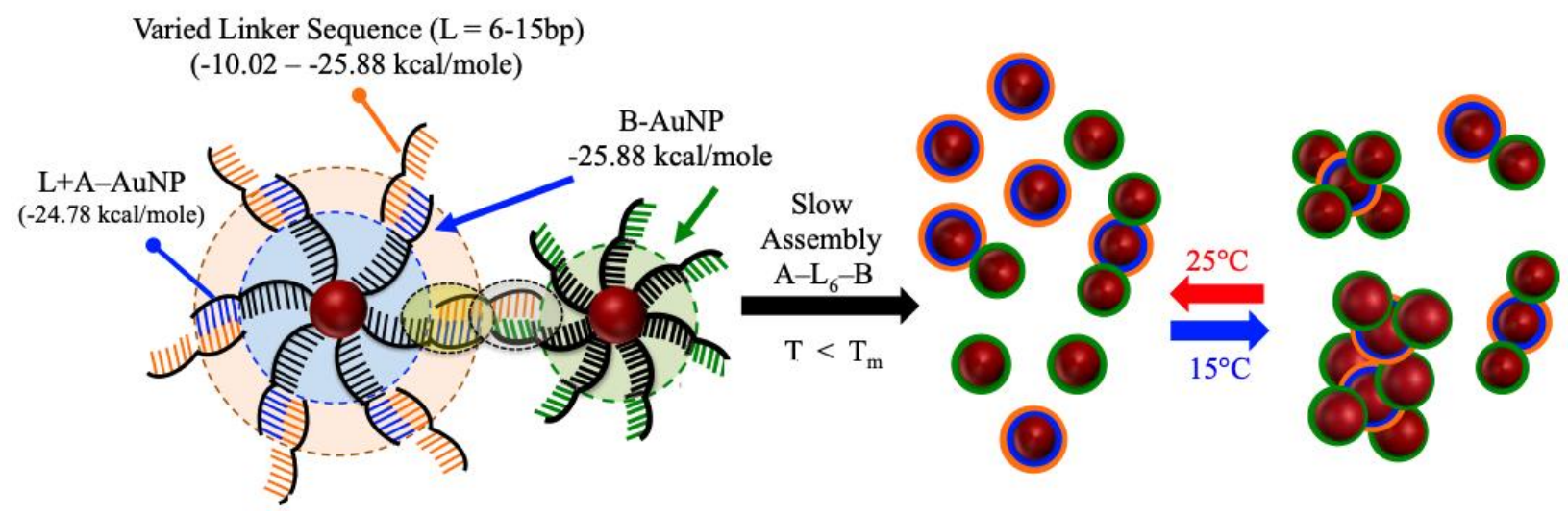

The AuNPs were synthesized via a traditional approaches ${ }^{29}$ to produce a spherical nanoparticle with diameter (D) of $11.3 \pm 1.8 \mathrm{~nm}$. Figure 1a shows a TEM micrograph of the AuNPs and their associated statistical analysis. Next, ssDNA functionalization with A- and Btype was confirmed by UV-vis and DLS. The UV-vis measures the surface plasmon resonance (SPR) band of the AuNP arising from the collective oscillation of conduction electrons of the 
AuNP surface, which is a function of dielectric properties, ${ }^{49}$ particle size and shape ${ }^{50}$ and interparticle distance. ${ }^{51}$ DLS on the other hand estimates the total hydrodynamic diameter $\left(D_{h}\right)$ of the DNA-AuNP conjugate. Figure $1 \mathrm{~b}$ highlights two unique UV-vis signatures, the SPR of the AuNPs $(\sim 520 \mathrm{~nm})$, and a weaker absorbance related to the ssDNA. $(\sim 260 \mathrm{~nm})$. Figure 1c shows the DLS results which measured $D_{\mathrm{h}} \sim 12 \mathrm{~nm}$ (i) for the citrate capped AuNP, $D_{\mathrm{h}} \sim 24$ (ii) for AAuNP and $\sim 21 \mathrm{~nm}$ (iii) for B-AuNP. These values correspond to $6 \sim 7 \mathrm{~nm}$ thick ssDNA layer, which is consistent for ssDNA of this length. ${ }^{29,52}$ Further, the quantity of DNA per AuNP was determined via a fluorescence based protocol. ${ }^{53}$ Using A'- and B'-Cy3 modified ssDNA complements, we determined $\sim 70( \pm 12)$ ssDNA per AuNP for the conjugates in this study (Table S1).
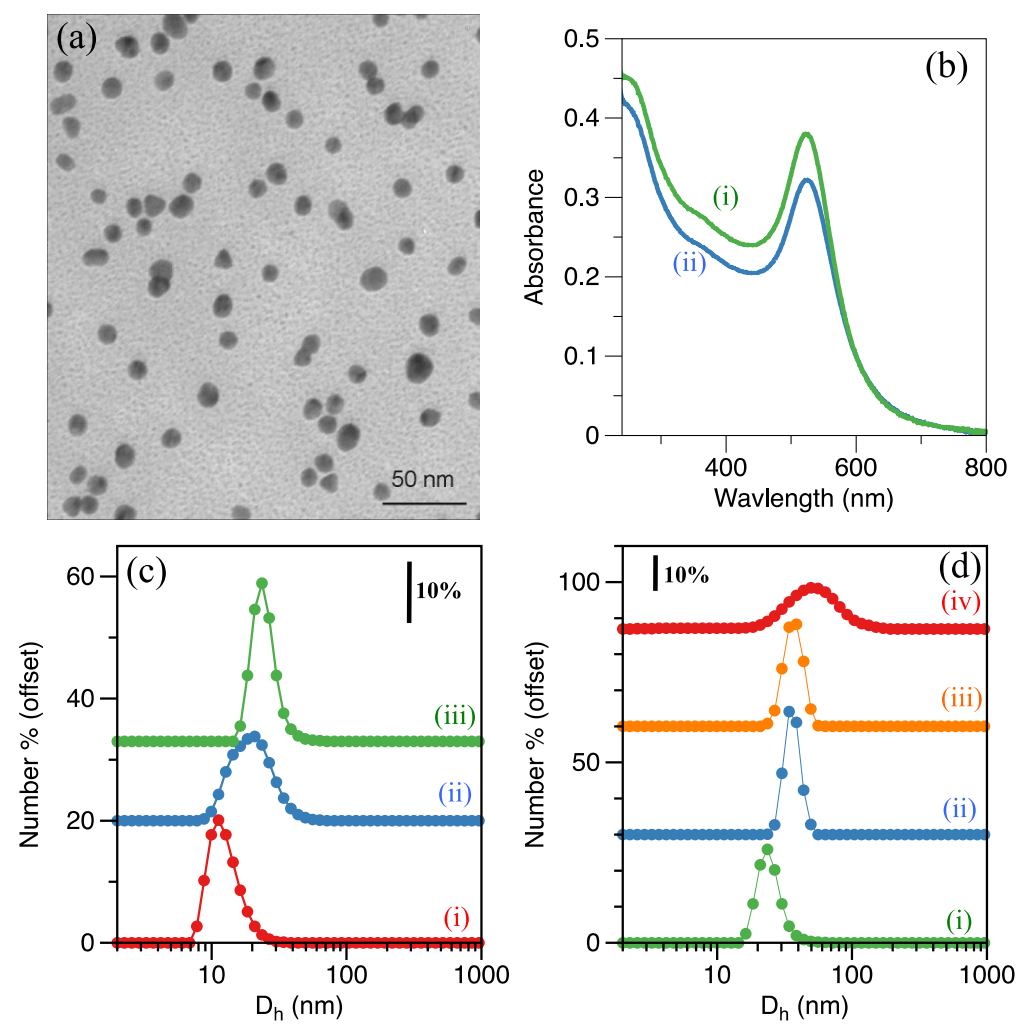

Figure 1. (a) Representative TEM micrograph for the cit-AuNPs used in this study ( $D=11.3 \pm$ $1.8 \mathrm{~nm}$ ). (b) UV-vis spectra of B-AuNPs (i) and $\mathrm{L}_{15}-\mathrm{A}-\mathrm{AuNPs}$ (ii). (c) DLS for cit-AuNPs (i), 
B- (ii) and A- (iii) functionalized AuNPs. (d) DLS results for A-AuNPs (i) after addition of linker $\mathrm{L}_{6}$ (ii), $\mathrm{L}_{9}$ (iii) and $\mathrm{L}_{12}$ (iv), ( $\mathrm{L}_{15}$ not shown).

As illustrated above, the A-AuNP and B-AuNP are not complements, and instead, a ssDNA liker (L) must be added to initiate assembly. In our system, L was first incubated with AAuNP at molar ratios of $[\mathrm{L}]:[\mathrm{A}-\mathrm{AuNP}]=80$. Hybridization occurs due to the $15 \mathrm{bp}$ complementary anchor region (see Methods). This incubation was confirmed via DLS. Figure 1d shows the measured $D_{\mathrm{h}}$ increase to $\sim 34, \sim 38, \sim 49 \mathrm{~nm}$ for $\mathrm{L}_{6}, \mathrm{~L}_{9}$, and $\mathrm{L}_{12}$, respectively. Next, these L-A-AuNPs (denoted as A-L) were incubated with B-AuNPs at $[\mathrm{A}-\mathrm{L}]=[\mathrm{B}-\mathrm{AuNP}]$, and $\mathrm{UV}$-vis was used to monitor the assembly over $\sim 10 \mathrm{~h}$.

Figure 2 shows representative UV-vis signatures for the assembly using $\mathrm{L}_{12}$ (a), L9 (b), and $\mathrm{L}_{6}(\mathrm{c})$. In each case, the SPR decrease was observed as a function of linker length and time. The assembly show two distinct features: a dramatic decrease in SPR intensity over time and a red-shift of $11 \mathrm{~nm}$ for $\mathrm{L}_{15}$ and $9 \mathrm{~nm}$ for $\mathrm{L}_{12}$ and $\mathrm{L}_{9}$, respectively. Decrease in SPR intensity suggests that $\mathrm{A}-\mathrm{L}$ 9-15-B aggregates grow rapidly, inducing macroscopic aggregation, leading to significant shielding of SPR within the growing aggregate, light scattering, and sedimentation out of solution. The SPR red-shift is due largely in part to the interparticle distance becoming on the order of the AuNP diameter. With these characteristics in mind, the results suggest that smaller aggregates form in the $\mathrm{L}_{6}$ case as compared to $\mathrm{L}_{15}$. Further, DNA-mediated assembly was confirmed through thermal denaturation of the $\mathrm{A}-\mathrm{L}-\mathrm{B}$ linkages where subsequent disassembly of the clusters was performed with temperature and monitored via UV-vis. ${ }^{54-58}$ 
Figure $\mathrm{S} 1$ plots the $\mathrm{T}_{\mathrm{m}}$ for each linker system which were determined to be $32^{\circ} \mathrm{C}, 48^{\circ} \mathrm{C}, 54^{\circ} \mathrm{C}$ and $58^{\circ} \mathrm{C}$ for $\mathrm{L}_{6}-\mathrm{L}_{15}$, respectively.
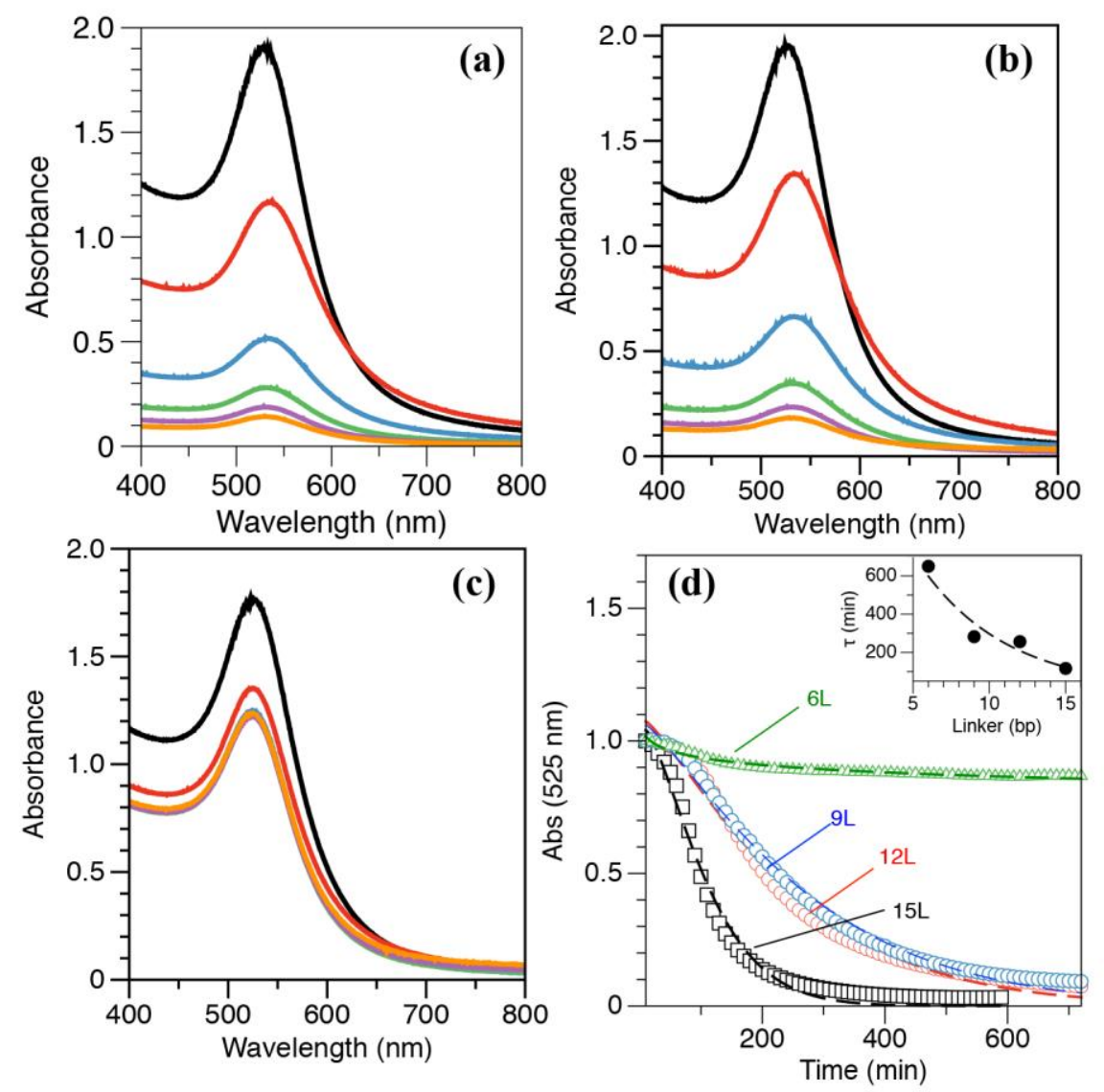

Figure 2. UV-vis for assembly of $\mathrm{A}-\mathrm{L}-\mathrm{B}$ clusters at $\mathrm{L}_{12}$ (a) $\mathrm{L}_{9}$ (b) and $\mathrm{L}_{6}$ (c), where absorbance is shown at 150 min time intervals ( $\mathrm{L}_{15}$ not shown, see SI). (d) Corresponding kinetics traces, fit to the Avrami nucleation model. Results indicate $\tau=650,282,256,116 \mathrm{~min}$ and $\mathrm{n}=0.02,1.2$, 1.2 and 1.4 for $\mathrm{L}_{6}-\mathrm{L}_{15}$, respectively.

We next compared the apparent assembly kinetics as monitored by SPR change. Figure $2 \mathrm{~d}$ shows the kinetic traces of the assembly, as monitored at $525 \mathrm{~nm}$. The results show that the rate of assembly varies with the linker length. The kinetic profiles were fit with the Avrami nucleation model,,$^{59} A b s=A b s_{0} e^{\left(\frac{x x_{0}}{n}\right) \div}$, , where $\mathrm{x}_{0}$ is onset reaction time, $\tau$ is characteristic nucleation time and $n$ is the dimension parameter. The kinetic fitting results determined $\tau=650$, 
282, 256 and 116 min. and $n=0.02,1.2,1.2$ and 1.4, for $\mathrm{L}_{6}-\mathrm{L}_{15}$, respectively. Results indicate that $\mathrm{A}-\mathrm{L}_{15}-\mathrm{B}$ assembly shows the fastest onset of aggregation, due to the decreased $\tau$ and an increased $n$, suggesting 3D nucleation and growth. Similar results are shown for $\mathrm{A}-\mathrm{L} 9-\mathrm{B}$ and $\mathrm{A}-$ $\mathrm{L}_{12}-\mathrm{B}$ showing a high $n$ value, however, the magnitude of $\tau$ was slightly slower than that of the A- $\mathrm{L}_{15}-\mathrm{B}$. In contrast, the assembly for $\mathrm{A}-\mathrm{L}_{6}-\mathrm{B}$ system is limited. The high $\tau$ and low $n$ value, suggest assembly of a decreased cluster size.

Due to these results and our goal of assembling smaller clusters, we focus the rest of the paper on the $\mathrm{L}_{6}$ assembly system. As notice above, the combination of A-AuNP and B-AuNP with the $\mathrm{L}_{6}$ linker has low hybridization energy and a $\mathrm{T}_{\mathrm{m}} \sim 32{ }^{\circ} \mathrm{C}$. Because this temperature is closer to room temperature than traditional assembly systems, we further probed assembly at lower temperatures. Changes to assembly temperature may induce changes to both the on/off kinetics and thermodynamic stability of the system. Briefly, $\mathrm{L}_{6}$-A-AuNPs and B-AuNPs were allowed to assemble at equal molar ratios, $\left[\mathrm{A}-\mathrm{L}_{6}\right]=[\mathrm{B}]$, at $15^{\circ} \mathrm{C}$ and $25^{\circ} \mathrm{C}$. Figure 3 shows UVvis spectra (a-b) where the SPR is monitored for $\sim 10 \mathrm{~h}$ at 15 (a) and $25^{\circ} \mathrm{C}$ (b). Comparatively, the results show a slight red-shift in the SPR of $2 \mathrm{~nm}$ when $\mathrm{A}-\mathrm{L}_{6}-\mathrm{B}$ is assembled at $15^{\circ} \mathrm{C}$ as opposed to no SPR shift when assembled at $25^{\circ} \mathrm{C}$. Furthermore, the UV-vis also shows a greater SPR intensity decrease at the lower assembly temperature. The kinetic profiles (c) are shown of the assembly at $15^{\circ} \mathrm{C}$ (i), $25^{\circ} \mathrm{C}$ (ii), along with a single, unhybridized [A- $\left.\mathrm{L}_{6}\right]$ control (iii). We can attribute the change in kinetics to the relationship between assembly temperature and the $T_{m}$. Assembly facilitated closer to the $T_{m}$ can be more reversible than assembly at lower temperatures where thermal energy is not significant enough to break linkages. Assembly is promoted at the lower temperature as shown through the more significant slope in the kinetic profile as compared 
to room temperature and the hybridized control. Therefore $\mathrm{A}-\mathrm{L}_{6}-\mathrm{B}$ clusters at $15^{\circ} \mathrm{C}$ may be more stable and may not dissociate as easily as clusters formed at $25^{\circ} \mathrm{C}$.
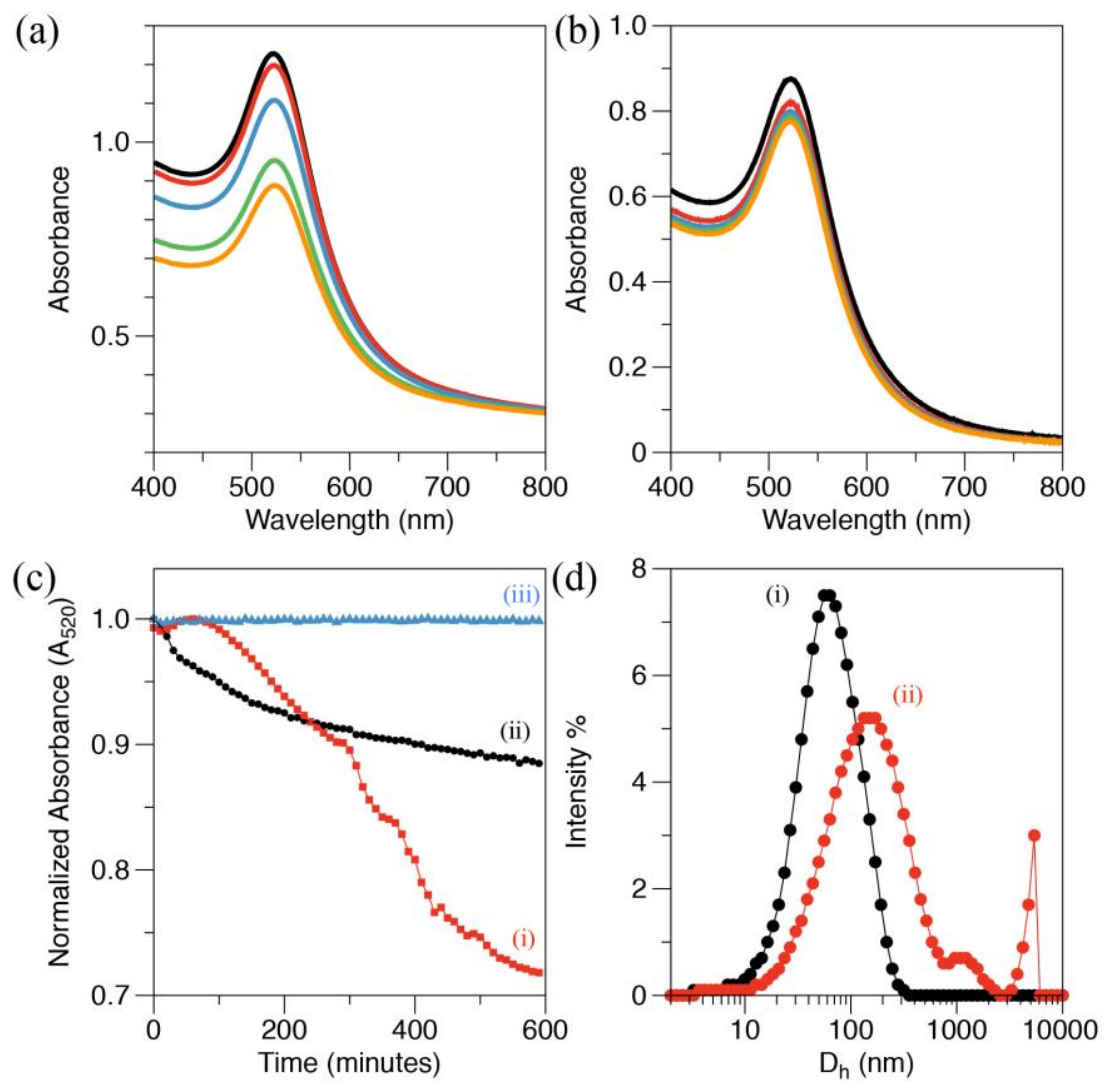

Figure 3. Representative UV-Vis spectra over the course of an assembly for $\mathrm{A}-\mathrm{L}_{6}-\mathrm{B}$ clusters at 15 (a) and $25^{\circ} \mathrm{C}$ (b). (c) UV-vis monitoring of assembly kinetics for $\mathrm{A}-\mathrm{L}_{6}-\mathrm{B}$ clusters at $15^{\circ} \mathrm{C}$ (i), $25^{\circ} \mathrm{C}$ (ii) in comparison with unhybridized control. (d) DLS of A- $\mathrm{L}_{6}-\mathrm{B}$ clusters assembled at $25^{\circ} \mathrm{C}$ (i) with $D_{\mathrm{h}}=56 \mathrm{~nm}$ and at $15^{\circ} \mathrm{C}$ (ii) with $D_{\mathrm{h}}=150$, and 1084 , respectively.

The size of the temperature-facilitated $\mathrm{A}-\mathrm{L}_{6}-\mathrm{B}$ clusters was measured via DLS. Figure 3d shows the DLS plot where the $15^{\circ} \mathrm{C}$ assembly showed primary $D_{\mathrm{h}}$ peaks at $\sim 150$, (ii), while the $25^{\circ} \mathrm{C}$ assembly showed a smaller overall $D_{\mathrm{h}}$ with only one peak at $\sim 56 \mathrm{~nm}$. While these are the most prominent peaks observed at these temperatures it is important to note that in both assembly systems, the spectra are broad, indicating possible the presence of multiple structures, sizes or cluster morphologies. 
To overcome the possible heterogeneity of the $\mathrm{A}-\mathrm{L}_{6}-\mathrm{B}$ clusters, sucrose gradient ultracentrifugation (UC) was explored as a separation strategy. Recently UC has been used to separate AuNP assemblies, ${ }^{43,60-63}$ as well as DNA Origami ${ }^{60}$ and quantum dot (QD) conjugates. ${ }^{24}$ Figure 4 shows a schematic (a) of UC-band position determination as well as resulting UC separations for single un-hybridized A-AuNP (b) and $\mathrm{A}-\mathrm{L}_{6}-\mathrm{B}$ clusters assembled at $25^{\circ} \mathrm{C}$ (c) and $15^{\circ} \mathrm{C}(\mathrm{d})$. Overall band position in the gradient was calculated by using $d=\frac{d_{\text {total }} d_{\text {band }}}{w_{\text {total }}}$, where $d_{\text {total }}$ is the total length of the tube, $d_{\text {band }}$ is the distance from bottom of the tube to the band center and $w_{\text {total }}$ is the total width of the tube. Results show distinct differences in the band position between the two assembly temperatures. As shown, the band for $\mathrm{A}-\mathrm{L}_{6}-\mathrm{B}$ clusters assembled at $25^{\circ} \mathrm{C}$ (c) travel a short distance in a single, uniform band, while clusters assembled at $15^{\circ} \mathrm{C}$ (d) travel further through the gradient and the band disperses significantly. The $\mathrm{A}-\mathrm{L}_{6}-\mathrm{B}$ clusters assembled at $25^{\circ} \mathrm{C}$ traveled only a short distance $\left(\mathrm{d}_{\text {band }}=0.29\right)$, suggesting few clusters or assemblies under these conditions. In contrast, the $\mathrm{A}-\mathrm{L}_{6}-\mathrm{B}$ clusters assembled at $15^{\circ} \mathrm{C}$ showed $\left(\mathrm{d}_{\text {band }}=1.44\right)$, indicating a larger (i.e., heavier) cluster, which also showed broadening. A plot of $\mathrm{d}_{\text {band }}$ position over time is shown in Figure 4c. 


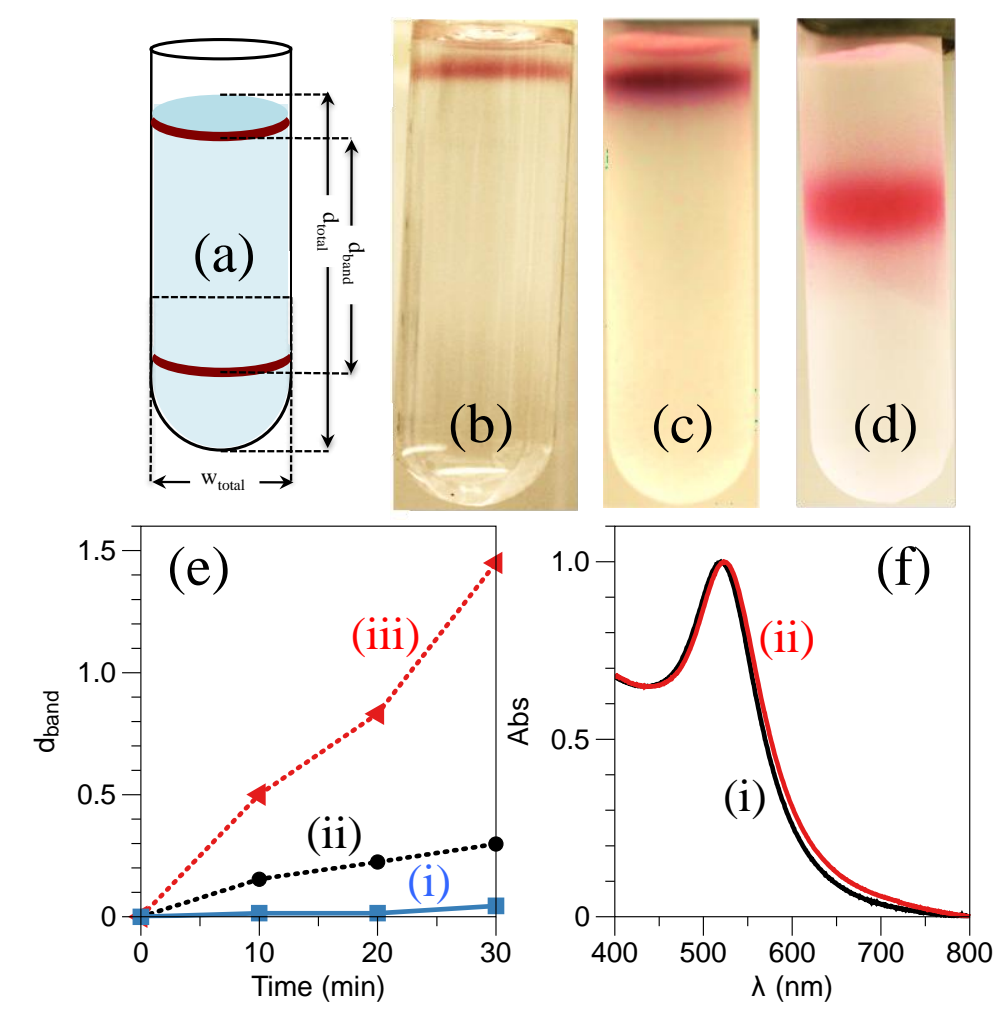

Figure 4. (a) Schematic of UC-band position determination. Photograph of UC results for gradient separation for $\mathrm{L}_{6}-\mathrm{A}-\mathrm{AuNPs}$ (b), and $\mathrm{A}-\mathrm{L}_{6}-\mathrm{B}$ clusters assembled at $25^{\circ} \mathrm{C}$ (c) and $15^{\circ} \mathrm{C}$ (d). (e) Plot of UC $d$ traveled for the $\mathrm{L}_{6}-\mathrm{A}-\mathrm{AuNPs}$ (i), and $\mathrm{A}-\mathrm{L}_{6}-\mathrm{B}$ at $15^{\circ} \mathrm{C}$ (ii) and $25^{\circ} \mathrm{C}$ (iii). (c) $\mathrm{UV}$-vis plot of $\mathrm{A}-\mathrm{L}_{6}-\mathrm{B}$ assembly products at $25^{\circ} \mathrm{C}$ (i) and $15^{\circ} \mathrm{C}$ (ii).

To investigate the morphologies of the $\mathrm{A}-\mathrm{L}_{6}-\mathrm{B}$ clusters created as a function of temperature, the samples were collected after UC separation and studied via TEM. Figure 5 shows representative TEM micrographs (a) of the $\mathrm{A}-\mathrm{L}_{6}-\mathrm{B}$ clusters assembled at $25^{\circ} \mathrm{C}$ (i-ii) and $15^{\circ} \mathrm{C}$ (iii-iv). Additional micrographs are shown in Figure S4 and Figure S5. We can observe differences between the resulting geometries for the two systems. When assembled at $25{ }^{\circ} \mathrm{C}$ (i,ii), a major component of the assembly is individual AuNPs. A small population shows groupings of AuNPs. In contrast, the results when assembled at $15^{\circ} \mathrm{C}$, show clusters that are larger and more structured. 
(a)
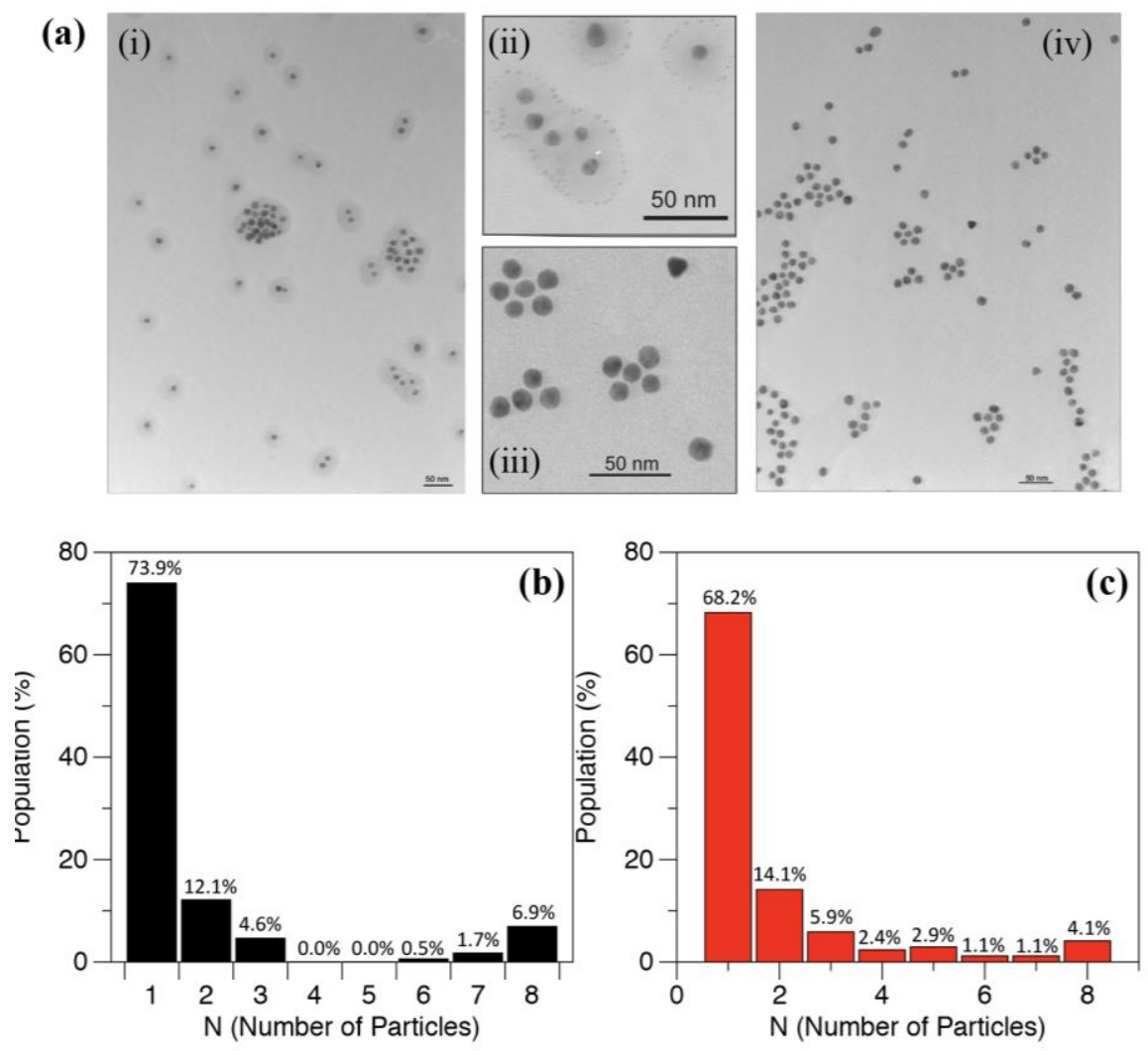

Figure 5. (a) Representative TEM images for the $\mathrm{A}-\mathrm{L}_{6}-\mathrm{B}$ assembled at $25^{\circ} \mathrm{C}$ (i-ii) and $15^{\circ} \mathrm{C}$ (iiiiv). Corresponding statistical analysis of observed clusters, with quantity of individual AuNP (n) tabulated for assembly at 25 (b) and $15^{\circ} \mathrm{C}(\mathrm{c})$.

Figure 5 shows the results of statistical analysis of the micrographs, where the number of AuNP per cluster $(\mathrm{N})$ was determined. The assembly at $15^{\circ} \mathrm{C}$ show a decreased population (\%) of single particles and an increased population $(\%)$ of $\mathrm{A}-\mathrm{L}_{6}-\mathrm{B}$ clusters with a higher degree of order. While a high population $(\%)$ of individual AuNPs $(N=1)$ is shown for both $15^{\circ} \mathrm{C}$ and $25^{\circ} \mathrm{C}$ assemblies, the change is significant in the $N=2-7$, region. Comparatively, a larger number of clusters with $N=2-7$ are found to assemble at $15^{\circ} \mathrm{C}$ relative to $25^{\circ} \mathrm{C}$, ultimately yielding a $13 \%$ increase in cluster size. 
Collectively, these results demonstrate the tailorability of the DNA-mediated cluster assembly by controlling assembly kinetics. By assembling the AuNP using linkers with melting temperatures close to room temperature, only small aggregates (clusters) were observed. One challenge is the persistence of single isolated AuNPs in the final cluster populations (TEM), despite uniform bands in the UC separation. We speculate that a small percentage of AuNPs may be de hybridizing during separation and TEM sampling, or more likely, this distribution in $\mathrm{N}$ is an indication of the on/off assembly rate in the clusters. While the relationship between linker length and melting temperature is not novel, the use of weakly hybridizing linkers to manipulate assembly kinetics may allow researchers a useful tool when designing a multiassembly system in which external stimuli (temperature) is used to activate assembly, such as in dynamic assembly or reconfiguration, ${ }^{64}$ or in smart assembly.., 65

\section{Conclusions}

In conclusion, DNA-mediated assembly of nanoparticle clusters via manipulation of assembly kinetics was described. Implementation of variable DNA linker length $(\mathrm{L}=6-15)$ provided an attractive means for controlling assembly and allowed for the control of cluster growth. Assembly using $\mathrm{L}=9-15$ resulted in classical uncontrolled aggregation, whereas assembly at $\mathrm{L}=6$ showed slow growth of cluster. The $\mathrm{L}=6$ assembly was further studied at 15 and $25^{\circ} \mathrm{C}$, with better cluster stability at the lower temperatures. The clusters were further separated by sucrose gradient ultracentrifugation, and cluster growth was confirmed by TEM confirmed. The number of nanoparticles per cluster $(N)$ was determined to range between $2-7$ by at $15{ }^{\circ} \mathrm{C}$, but single nanoparticles were also observed. These results suggest that it may be possible to assembly small clusters of nanoparticles in a straightforward one-step manner by 
kinetic control, as opposed to approaches using multiple purification steps of quantized numbers of DNA per nanoparticle.

\section{Acknowledgments}

This work was supported by an IGERT grant from the National Science Foundation (DGE1068780). A.J.L. thanks the NSF for the IGERT fellowship. We thank Prof. Mark J. Bowick for discussions on assembly morphology. This work was supported in part by the Air Force Office of Scientific Research (FA9550-10-1-0033). M.M.M. acknowledges additional support from the NSF (DMR-1410569, DBI-1531757) and a Syracuse University Deans Professor of Science fellowship.

\section{TOC Graphic:}

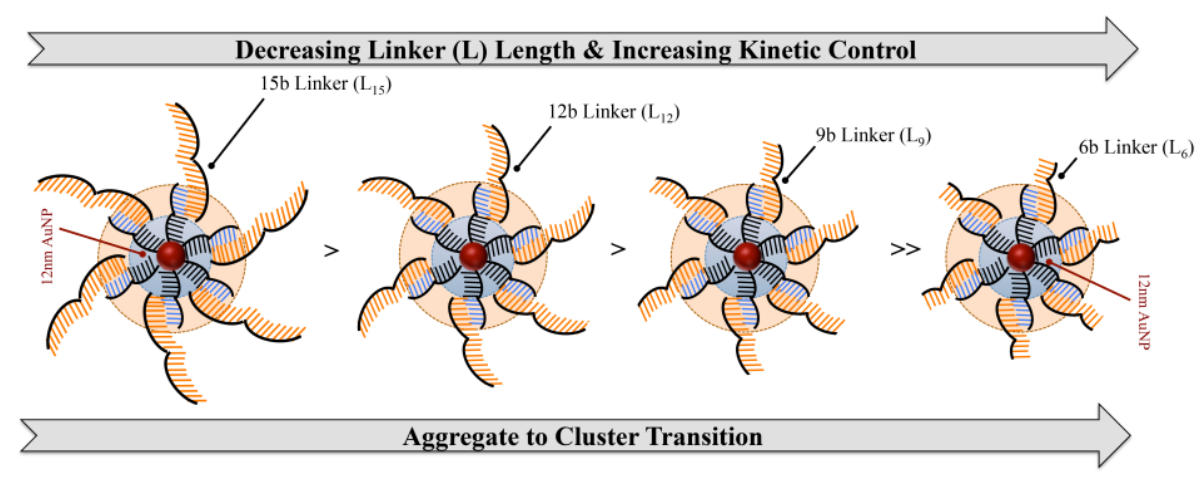




\section{References}

(1) Kuzyk, A.; Schreiber, R.; Fan, Z.; Pardatscher, G.; Roller, E.-M.; Hogele, A.; Simmel, F. C.; Govorov, A. O.; Liedl, T. DNA-Based Self-Assembly of Chiral Plasmonic Nanostructures with Tailored Optical Response. Nature 2012, 483, 311-314.

(2) Zhang, Y.; Lu, F.; Yager, K. G.; van der Lelie, D.; Gang, O. A General Strategy for the DNA-Mediated Self-Assembly of Functional Nanoparticles into Heterogeneous Systems. Nat Nano 2013, 8, 865-872.

(3) Yeh, Y.-C.; Creran, B.; Rotello, V. M. Gold Nanoparticles: Preparation, Properties, and Applications in Bionanotechnology. Nanoscale 2012, 4, 1871-1880.

(4) Ma, L.; Li, F.; Fang, T.; Zhang, J.; Wang, Q. Controlled Self-Assembly of Proteins into Discrete Nanoarchitectures Templated by Gold Nanoparticles via Monovalent Interfacial Engineering. ACS Appl. Mater. Interfaces 2015, 7, 11024-11031.

(5) Hamner, K. L.; Maye, M. M. Thermal Aggregation Properties of Nanoparticles Modified with Temperature Sensitive Copolymers. Langmuir 2013, 29, 15217-15223.

(6) Hu, J.; Wu, T.; Zhang, G.; Liu, S. Efficient Synthesis of Single Gold Nanoparticle Hybrid Amphiphilic Triblock Copolymers and Their Controlled Self-Assembly. J. Am. Chem. Soc. 2012, 134, 7624-7627.

(7) Dey, P.; Blakey, I.; Thurecht, K. J.; Fredericks, P. M. Self-Assembled Hyperbranched Polymer-Gold Nanoparticle Hybrids: Understanding the Effect of Polymer Coverage on Assembly Size and SERS Performance. Langmuir 2013, 29, 525-533.

(8) Auyeung, E.; Li, T. I. N. G.; Senesi, A. J.; Schmucker, A. L.; Pals, B. C.; de la Cruz, M. O.; Mirkin, C. A. DNA-Mediated Nanoparticle Crystallization into Wulff Polyhedra. Nature 2014, 505, 73-77.

(9) Tan, L. H.; Xing, H.; Lu, Y. DNA as a Powerful Tool for Morphology Control, Spatial Positioning, and Dynamic Assembly of Nanoparticles. Acc. Chem. Res. 2014, 47, 18811890.

(10) Pei, H.; Li, F.; Wan, Y.; Wei, M.; Liu, H.; Su, Y.; Chen, N.; Huang, Q.; Fan, C. Designed Diblock Oligonucleotide for the Synthesis of Spatially Isolated and Highly Hybridizable Functionalization of DNA-Gold Nanoparticle Nanoconjugates. J. Am. Chem. Soc. 2012, 134, 11876-11879.

(11) Ross, M. B.; Ku, J. C.; Vaccarezza, V. M.; Schatz, G. C.; Mirkin, C. A. Nanoscale Form Dictates Mesoscale Function in Plasmonic DNA-nanoparticle Superlattices. Nat Nano 2015, 10, 453-458.

(12) Lan, X.; Chen, Z.; Liu, B.-J.; Ren, B.; Henzie, J.; Wang, Q. DNA-Directed Gold Nanodimers with Tunable Sizes and Interparticle Distances and Their Surface Plasmonic Properties. Small 2013, 9, 2308-2315.

(13) Zhang, Y.; Pal, S.; Srinivasan, B.; Vo, T.; Kumar, S.; Gang, O. Selective Transformations between Nanoparticle Superlattices via the Reprogramming of DNA-Mediated Interactions. Nat Mater 2015, 14, 840-847.

(14) Nykypanchuk, D.; Maye, M. M.; van der Lelie, D.; Gang, O. DNA-Guided Crystallization of Colloidal Nanoparticles. Nature 2008, 451, 549-552.

(15) Lalander, C. H.; Zheng, Y.; Dhuey, S.; Cabrini, S.; Bach, U. DNA-Directed SelfAssembly of Gold Nanoparticles onto Nanopatterned Surfaces: Controlled Placement of Individual Nanoparticles into Regular Arrays. ACS Nano 2010, 4, 6153-6161. 
(16) Aldaye, F. A.; Sleiman, H. F. Dynamic DNA Templates for Discrete Gold Nanoparticle Assemblies: Control of Geometry, Modularity, Write/Erase and Structural Switching. $J$. Am. Chem. Soc. 2007, 129, 4130-4131.

(17) Shen, X.; Song, C.; Wang, J.; Shi, D.; Wang, Z.; Liu, N.; Ding, B. Rolling Up Gold Nanoparticle-Dressed DNA Origami into Three-Dimensional Plasmonic Chiral Nanostructures. J. Am. Chem. Soc. 2012, 134, 146-149.

(18) Kim, J.-Y.; Lee, J.-S. Synthesis and Thermally Reversible Assembly of DNA-Gold Nanoparticle Cluster Conjugates. Nano Lett. 2009, 9, 4564-4569.

(19) Trantakis, I. A.; Bolisetty, S.; Mezzenga, R.; Sturla, S. J. Reversible Aggregation of DNADecorated Gold Nanoparticles Controlled by Molecular Recognition. Langmuir 2013, 29, 10824-10830.

(20) Liu, Y.; Han, X.; He, L.; Yin, Y. Thermoresponsive Assembly of Charged Gold Nanoparticles and Their Reversible Tuning of Plasmon Coupling. Angew. Chem. Int. Ed. 2012, 51, 6373-6377.

(21) Sun, D.; Gang, O. Binary Heterogeneous Superlattices Assembled from Quantum Dots and Gold Nanoparticles with DNA. J. Am. Chem. Soc. 2011, 133, 5252-5254.

(22) Zhang, C.; Macfarlane, R. J.; Young, K. L.; Choi, C. H. J.; Hao, L.; Auyeung, E.; Liu, G.; Zhou, X.; Mirkin, C. A. A General Approach to DNA-Programmable Atom Equivalents. Nat Mater 2013, 12, 741-746.

(23) Coopersmith, K.; Han, H.; Maye, M. M. Stepwise Assembly and Characterization of DNA Linked Two-Color Quantum Dot Clusters. Langmuir 2015, 31, 7463-7471.

(24) Doane, T. L.; Alam, R.; Maye, M. M. Functionalization of Quantum Rods with Oligonucleotides for Programmable Assembly with DNA Origami. Nanoscale 2015, 7, 2883-2888.

(25) Nykypanchuk, D.; Maye, M. M.; van der Lelie, D.; Gang, O. DNA-Guided Crystallization of Colloidal Nanoparticles. Nature 2008, 451, 549-552.

(26) Gandra, N.; Abbas, A.; Tian, L.; Singamaneni, S. Plasmonic Planet-Satellite Analogues: Hierarchical Self-Assembly of Gold Nanostructures. Nano Lett. 2012, 12, 2645-2651.

(27) Akiyama, Y.; Shikagawa, H.; Kanayama, N.; Takarada, T.; Maeda, M. Modulation of Interparticle Distance in Discrete Gold Nanoparticle Dimers and Trimers by DNA SingleBase Pairing. Small 2015, 11, 3153-3161.

(28) Jin, R.; Wu, G.; Li, Z.; Mirkin, C. A.; Schatz, G. C. What Controls the Melting Properties of DNA-Linked Gold Nanoparticle Assemblies? J. Am. Chem. Soc. 2003, 125, 16431654.

(29) Maye, M. M.; Nykypanchuk, D.; van der Lelie, D.; Gang, O. A Simple Method for Kinetic Control of DNA-Induced Nanoparticle Assembly. J. Am. Chem. Soc. 2006, 128, 1402014021.

(30) Prigodich, A. E.; Lee, O.-S.; Daniel, W. L.; Seferos, D. S.; Schatz, G. C.; Mirkin, C. A. Tailoring DNA Structure To Increase Target Hybridization Kinetics on Surfaces. J. Am. Chem. Soc. 2010, 132, 10638-10641.

(31) Leunissen, M. E.; Dreyfus, R.; Sha, R.; Seeman, N. C.; Chaikin, P. M. Quantitative Study of the Association Thermodynamics and Kinetics of DNA-Coated Particles for Different Functionalization Schemes. J. Am. Chem. Soc. 2010, 132, 1903-1913.

(32) Schade, N. B.; Holmes-Cerfon, M. C.; Chen, E. R.; Aronzon, D.; Collins, J. W.; Fan, J. A.; Capasso, F.; Manoharan, V. N. Tetrahedral Colloidal Clusters from Random Parking of Bidisperse Spheres. Phys Rev Lett 2013, 110, 148303. 
(33) Buchkremer, A.; Linn, M. J.; Timper, J. U.; Eckert, T.; Mayer, J.; Richtering, W.; von Plessen, G.; Simon, U. Synthesis and Internal Structure of Finite-Size DNA-Gold Nanoparticle Assemblies. J. Phys. Chem. C 2014, 118, 7174-7184.

(34) Hurst, S. J.; Lytton-Jean, A. K. R.; Mirkin, C. A. Maximizing DNA Loading on a Range of Gold Nanoparticle Sizes. Anal. Chem. 2006, 78, 8313-8318.

(35) Zanchet, D.; Micheel, C. M.; Parak, W. J.; Gerion, D.; Alivisatos, A. P. Electrophoretic Isolation of Discrete Au Nanocrystal/DNA Conjugates. Nano Lett. 2001, 1, 32-35.

(36) Zanchet, D.; Micheel, C. M.; Parak, W. J.; Gerion, D.; Williams, S. C.; Alivisatos, A. P. Electrophoretic and Structural Studies of DNA-Directed Au Nanoparticle Groupings. J. Phys. Chem. B 2002, 106, 11758-11763.

(37) Maye, M. M.; Nykypanchuk, D.; van der Lelie, D.; Gang, O. DNA-Regulated Micro- and Nanoparticle Assembly. Small Weinh. Bergstr. Ger. 2007, 3, 1678-1682.

(38) Srivastava, S.; Nykypanchuk, D.; Maye, M. M.; Tkachenko, A. V.; Gang, O. SuperCompressible DNA Nanoparticle Lattices. Soft Matter 2013.

(39) Yao, D.; Wang, B.; Xiao, S.; Song, T.; Huang, F.; Liang, H. What Controls the "Off/On Switch" in the Toehold-Mediated Strand Displacement Reaction on DNA Conjugated Gold Nanoparticles? Langmuir 2015, 31, 7055-7061.

(40) Lam, M. K.; Gadzikwa, T.; Nguyen, T.; Kausar, A.; Alladin-Mustan, B. S.; Sikder, M. D.; Gibbs-Davis, J. M. Tuning Toehold Length and Temperature to Achieve Rapid, Colorimetric Detection of DNA from the Disassembly of DNA-Gold Nanoparticle Aggregates. Langmuir 2016, 32, 1585-1590.

(41) Pellegrino, T.; Sperling, R. A.; Alivisatos, A. P.; Parak, W. J. Gel Electrophoresis of GoldDNA Nanoconjugates. J. Biomed. Biotechnol. 2007, 2007, 9.

(42) Claridge, S. A.; Liang, H. W.; Basu, S. R.; Fréchet, J. M. J.; Alivisatos, A. P. Isolation of Discrete Nanoparticle-DNA Conjugates for Plasmonic Applications. Nano Lett. 2008, 8, 1202-1206.

(43) Chen, G.; Wang, Y.; Tan, L. H.; Yang, M.; Tan, L. S.; Chen, Y.; Chen, H. High-Purity Separation of Gold Nanoparticle Dimers and Trimers. J. Am. Chem. Soc. 2009, 131, 42184219.

(44) Brocher, J. BioVoxxel Image Processing and Analysis Toolbox. In; 2015.

(45) Mirkin, C. A.; Letsinger, R. L.; Mucic, R. C.; Storhoff, J. J. A DNA-Based Method for Rationally Assembling Nanoparticles into Macroscopic Materials. Nature 1996, 382, 607 609.

(46) Alivisatos, A. P.; Johnsson, K. P.; Peng, X.; Wilson, T. E.; Loweth, C. J.; Bruchez, M. P. .; Schultz, P. G. Organization of "Nanocrystal Molecules" Using DNA. Nature 1996, 382, 609-611.

(47) Xiong, H.; van der Lelie, D.; Gang, O. Phase Behavior of Nanoparticles Assembled by DNA Linkers. Phys Rev Lett 2009, 102, 015504.

(48) Sun, D.; Gang, O. Binary Heterogeneous Superlattices Assembled from Quantum Dots and Gold Nanoparticles with DNA. J. Am. Chem. Soc. 2011, 133, 5252-5254.

(49) Schmitt, J.; Mächtle, P.; Eck, D.; Möhwald, H.; Helm, C. A. Preparation and Optical Properties of Colloidal Gold Monolayers. Langmuir 1999, 15, 3256-3266.

(50) Lee, K.-S.; El-Sayed, M. A. Gold and Silver Nanoparticles in Sensing and Imaging: Sensitivity of Plasmon Response to Size, Shape, and Metal Composition. J. Phys. Chem. B 2006, 110, 19220-19225. 
(51) Wessels, J. M.; Nothofer, H.-G.; Ford, W. E.; von Wrochem, F.; Scholz, F.; Vossmeyer, T.; Schroedter, A.; Weller, H.; Yasuda, A. Optical and Electrical Properties of ThreeDimensional Interlinked Gold Nanoparticle Assemblies. J. Am. Chem. Soc. 2004, 126, 3349-3356.

(52) Rubinstein, M.; Colby, R. H. Polymer Physics; Oxford University Press: New York, 2003.

(53) Hurst, S. J.; Lytton-Jean, A. K. R.; Mirkin, C. A. Maximizing DNA Loading on a Range of Gold Nanoparticle Sizes. Anal. Chem. 2006, 78, 8313-8318.

(54) Gibbs-Davis, J. M.; Schatz, G. C.; Nguyen, S. T. Sharp Melting Transitions in DNA Hybrids without Aggregate Dissolution: Proof of Neighboring-Duplex Cooperativity. $J$. Am. Chem. Soc. 2007, 129, 15535-15540.

(55) Park, S. Y.; Gibbs-Davis, J. M.; Nguyen, S. T.; Schatz, G. C. Sharp Melting in DNALinked Nanostructure Systems: Thermodynamic Models of DNA-Linked Polymers. $J$. Phys. Chem. B 2007, 111, 8785-8791.

(56) Jin, R.; Wu, G.; Li, Z.; Mirkin, C. A.; Schatz, G. C. What Controls the Melting Properties of DNA-Linked Gold Nanoparticle Assemblies? J. Am. Chem. Soc. 2003, 125, $1643-$ 1654.

(57) Storhoff, J. J.; Lazarides, A. A.; Mucic, R. C.; Mirkin, C. A.; Letsinger, R. L.; Schatz, G. C. What Controls the Optical Properties of DNA-Linked Gold Nanoparticle Assemblies? J. Am. Chem. Soc. 2000, 122, 4640-4650.

(58) Lei, Q.; Ren, C.; Su, X.; Ma, Y. Crowding-Induced Cooperativity in DNA Surface Hybridization. Sci. Rep. 2015, 5, 9217.

(59) Avrami, M. Kinetics of Phase Change. II Transformation-Time Relations for Random Distribution of Nuclei. J. Chem. Phys. 1940, 8, 212-224.

(60) Ko, S. H.; Vargas-Lara, F.; Patrone, P. N.; Stavis, S. M.; Starr, F. W.; Douglas, J. F.; Liddle, J. A. High-Speed, High-Purity Separation of Gold Nanoparticle-DNA Origami Constructs Using Centrifugation. Soft Matter 2014, 10, 7370-7378.

(61) Pandey, S.; Thakur, M.; Shah, R.; Oza, G.; Mewada, A.; Sharon, M. A Comparative Study of Economical Separation and Aggregation Properties of Biologically Capped and Thiol Functionalized Gold Nanoparticles: Selecting the Eco-Friendly Trojan Horses for Biological Applications. Colloids Surf. B Biointerfaces 2013, 109, 25-31.

(62) Kowalczyk, B.; Lagzi, I.; Grzybowski, B. A. Nanoseparations: Strategies for Size And/or Shape-Selective Purification of Nanoparticles. Curr. Opin. Colloid Interface Sci. 2011, 16, 135-148.

(63) Wu, W.; Huang, J.; Wu, L.; Sun, D.; Lin, L.; Zhou, Y.; Wang, H.; Li, Q. Two-Step Sizeand Shape-Separation of Biosynthesized Gold Nanoparticles. Sep. Purif. Technol. 2013, $106,117-122$.

(64) Maye, M. M.; Kumara, M. T.; Nykypanchuk, D.; Sherman, W. B.; Gang, O. Switching Binary States of Nanoparticle Superlattices and Dimer Clusters by DNA Strands. Nat. Nanotechnol. 2009, 5, 116-120.

(65) Hamner, K. L.; Alexander, C. M.; Coopersmith, K.; Reishofer, D.; Provenza, C.; Maye, M. M. Using Temperature-Sensitive Smart Polymers to Regulate DNA-Mediated Nanoassembly and Encoded Nanocarrier Drug Release. ACS Nano 2013, 7, 7011-7020. 